\title{
Simulation of delamination-migration and core crushing in a CFRP sandwich structure
}

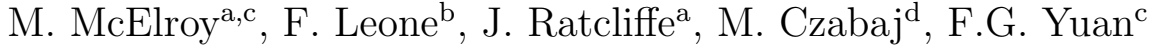 \\ ${ }^{a}$ Durability, Damage Tolerance, and Reliability Branch, NASA Langley Research Center, \\ Hampton, VA USA \\ ${ }^{b}$ Structural Mechanics and Concepts Branch, NASA Langley Research Center, Hampton, \\ VA USA \\ ${ }^{c}$ Department of Mechanical and Aerospace Engineering, North Carolina State University, \\ Raleigh, NC USA \\ ${ }^{d}$ Department of Mechanical Engineering, University of Utah, Salt Lake City, UT USA
}

\begin{abstract}
Following the onset of damage caused by an impact load on a composite laminate structure, delaminations often form propagating outwards from the point of impact and in some cases can migrate via matrix cracks between plies as they grow. The goal of the present study is to develop an accurate finite element modeling technique for simulation of the delamination-migration phenomena in laminate impact damage processes. An experiment was devised where, under a quasi-static indentation load, an embedded delamination in the facesheet of a laminate sandwich specimen migrates via a transverse matrix crack and then continues to grow on a new ply interface. The quasistatic nature of the indentation results in structural behavior equivalent to that seen in low-velocity impact and also allows for highly detailed real time damage characterization. Several finite element damage simulation methods were investigated. Comparing the experimental results with those of the different models reveals certain modeling features that are important to include in a numerical simulation of delamination-migration and some that may be neglected.
\end{abstract}

Keywords: A. Laminates, A. Honeycomb, C. Damage mechanics, B. Delamination

Pre-publication corresponding author: Mark McElroy mark.w.mcelroy@nasa.gov, +1 757864 9652, 2 W. Reid St, Mail Stop 188E Hampton, VA 23681

Post-publication corresponding author: Mark McElroy, mark.w.mcelroy@nasa.gov 


\section{Introduction}

Laminated composites are becoming common as lightweight alternatives to traditional materials for aerospace structures, although these materials are not without their drawbacks. Compared to metals, laminate composite materials are susceptible to damage resulting from transverse loads such as impact. To exacerbate this, in the case of low-velocity impact, damage often is not easily detectable or visible externally and if internal crack networks form, compressive strength of laminates can be significantly reduced [1]. For an efficient design, it is important to have tools to model internal laminate damage caused by low-velocity impact. If such tools are available, the need to rely on large factors of safety and testing for a structural design process is reduced.

Damage resulting from impact loads in composite laminates can take a number of forms including fiber failure, matrix cracks, matrix crushing, and delamination. A typical damage process resulting specifically from lowvelocity impact consists of the formation of a three dimensional internal network of interconnected matrix cracks and delaminations. A simple example of low-velocity impact damage in a laminate is shown in Figure 1. It is possible, in this type of damage process, that as the crack network is forming and the structure becomes increasingly degraded, growing delaminations may migrate via transverse matrix cracks and then continue propagating at a new ply interface $[2,3,4,5]$. Only a small number of attempts have been made at simulating this phenomenon [6], however, migration is a necessary feature for a generally applicable low-velocity impact damage model.

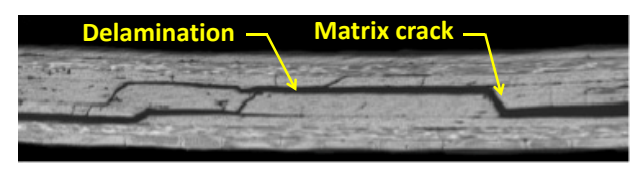

Figure 1: Example of damage in a laminate caused by low-velocity impact [7].

Two common techniques that have been used for numerical delamination simulation in laminates, namely cohesive zone modeling and the virtual crack closure technique (VCCT) [8, 9, 10], have been developed and successfully implemented into the finite element method (FEM) such that they can be used for general delamination simulations [11, 12, 13, 14, 15]. More recently, techniques based on discrete damage modeling methods such as the 
extended finite element method (XFEM) [16] or based on continuum damage mechanics [17] have been combined with cohesive zone modeling and VCCT for use in the simulation of more complex damage processes which include delamination-matrix crack interaction $[18,19,20,21]$. While success has been achieved to some degree in simulating progressive damage processes that include delamination-matrix crack interaction, there has been limited high resolution experimental data specifically on migration as an isolated event within a larger damage process to use as a validation basis for numerical simulation development. This level of detail is difficult to obtain as a progressive damage process caused by impact in laminates occurs very quickly and often only the final permanent damage state can be observed in detail. The sequence of events and intermittent states of damage during the load duration are of great interest in developing and validating a damage simulation tool that must predict the same process.

An experiment was devised where, under a quasi-static indentation load, an embedded delamination in the laminate facesheet of a honeycomb core sandwich test specimen migrates via a transverse matrix crack to a new ply interface and then continues to grow. The quasi-static nature of the indentation results in structural behavior equivalent to that seen in lowvelocity impact $[22,23,24]$. The sandwich core provides support to the loaded facesheet and results in a stable delamination-migration process that can be characterized in high detail in real time. The goal of the present study is to use the experimental data as the validation basis for the development of an accurate numerical simulation technique for delamination-migration in laminates in the context of low-velocity impact damage. Similar studies have been conducted involving modeling core crushing and impact damage on laminate sandwich structures [25, 26, 27, 28, 29, 30,31], however, high fidelity experimental data specific to delamination-migration have been unavailable previously.

A detailed three-dimensional finite element model of a test specimen was created to develop a simulation method for honeycomb core crushing. This model was modified into three variants each using a different approach for simulating delamination-migration in the facesheet. The migration simulation approaches included a cohesive zone model and two continuum damage mechanics models. The cohesive zone model was modified further to investigate the relevance of migration orientation and migration energy dissipation in a numerical simulation. The results from each model were compared to the experimental data in order to investigate which modeling features are 
important to include in a numerical simulation of delamination-migration and which can be neglected.

\section{Experimentation}

\subsection{Test Specimen Description}

The test specimen is illustrated in Figure 2. It consists of an aluminum honeycomb core sandwiched between two carbon fiber reinforced polymer (CFRP) facesheets with the top facesheet layup given by $\left[0_{3} / 90_{3} / 0\right]_{s}$ and the bottom facesheet layup given by $\left[0_{3} / 90_{3} / 45\right]_{s}$. Ply thickness is $0.11 \mathrm{~mm}$. A Teflon ${ }^{\circledR}$ insert is placed into the top (loaded) facesheet to act as a preexisting delamination immediately below the upper $0^{\circ}$ stack that contacts the indenter.

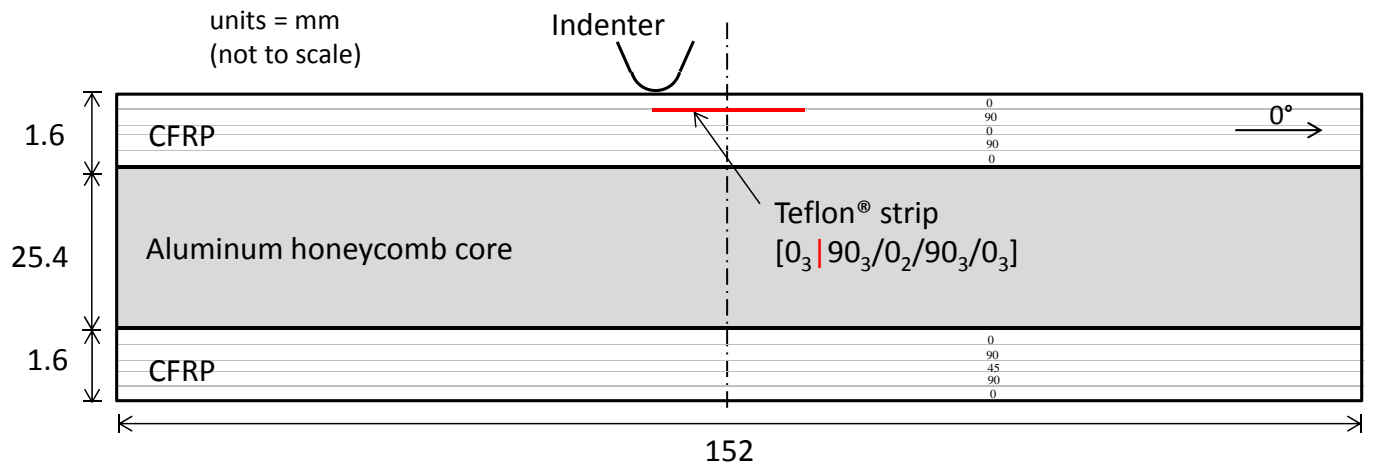

Figure 2: Test specimen configuration.

The sandwich core material, acts as a flexible foundation and provides support constraining facesheet deflection. The support from the core results in a localized deformed state where most of the energy from external loading is absorbed by honeycomb core crushing. The result, when an initial flaw is included, is that damage processes in the facesheet originating from the flaw are stable and can be well characterized in real time as they occur.

\subsection{Materials and Specimen Manufacture}

A $305 \mathrm{~mm}$ x $305 \mathrm{~mm}$ composite sandwich panel consisting of two IM7/8552 laminate facesheets and an aluminum honeycomb core (Hexcel type: CR III3/16-5052-.0015N-4.4) was fabricated. Teflon ${ }^{\circledR}$ insert strips, $0.012 \mathrm{~mm}$ thick 
and with a length of $25.4 \mathrm{~mm}$, were implanted in the top facesheet at the interface indicated in Figure 2. A limited number of specimens were manufactured that did not contain the Teflon ${ }^{\circledR}$ insert. By not introducing the initial delamination, these specimens could be used to observe core crushing damage behavior exclusively. The facesheets were first cured in a hot press using a cycle recommended by the material manufacturer and then co-bonded with the core using AF-555 film adhesive in a hot press using the adhesive manufacturer's recommended cure cycle. The sandwich panel was cut into specimens $152 \mathrm{~mm}$ long and $12.7 \mathrm{~mm}$ wide.

\subsection{Test Procedure}

Quasi-static indentation tests were performed using a servo hydraulic test stand equipped with an $11.5 \mathrm{kN}$ load cell. Specimens were positioned on a rigid base as shown in Figure 3 and indented with a $3 \mathrm{~mm}$-radius tip indenter under displacement control at a rate of $0.127 \mathrm{~mm} / \mathrm{min}$. In cases where the loaded facesheet contained an embedded delamination, the indenter was aligned with one of the Teflon ${ }^{\circledR}$ insert fronts as illustrated in Figure 2. Specimens with pristine facesheets (i.e., those without Teflon ${ }^{\circledR}$ inserts) were indented at their mid-span. Indenter force displacement response was recorded throughout the test using a sampling rate of $0.5 \mathrm{~Hz}$. The edges of the indented facesheets were painted white with diluted liquid correction fluid to highlight edge-view delamination and crack migration during a test. Facesheet damage was documented using two digital cameras equipped with macro lenses positioned on each side of a specimen. One test was performed where a digital image correlation system [32] was utilized to measure vertical

facesheet deformation. All tests had a maximum indenter displacement of $1.04 \mathrm{~mm}$.

\subsection{Specimen Behavior}

When the specimen is subjected to quasi-static indentation as described, a delamination-migration damage process occurs in the top facesheet that consists of the following: (1) an intralaminar matrix crack initiates at the end of the Teflon ${ }^{\circledR}$ strip and propagates down through the $90^{\circ}$ stack at an orientation angle of approximately $70^{\circ}$ from the horizontal until it is arrested when it reaches $0^{\circ}$ fibers, and (2) the crack turns and continues as a delamination that propagates on the new ply interface away from the migration location. The final state of facesheet damage from a representative test is 


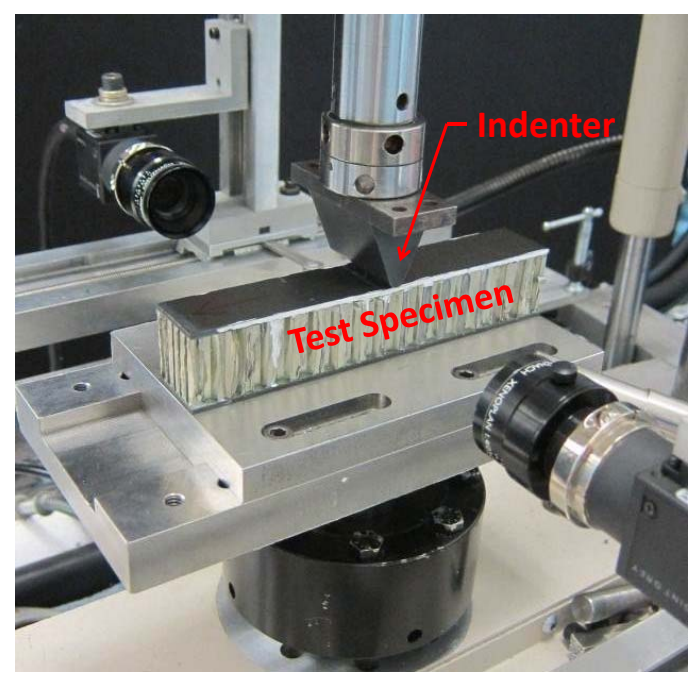

Figure 3: Test configuration of a composite honeycomb specimen under quasi-static indentation.

shown in Figure 4 and is similar to that seen in Figure 1. Gathering photographic data such as these throughout the entire test allows the migration and delamination growth to be compared in detail to finite element model results as shown in Section 4.

\section{Analysis}

Simulations of the indentation tests were performed using the commercial finite element analysis software Abaqus/Explicit ${ }^{\circledR} 6.13$ [33]. The purpose of these analyses was to compare results from the indentation experiments to several finite element damage modeling techniques and in doing so investigate what modeling features are necessary and which can be ignored for a delamination-migration simulation. This exercise resulted in an accurate finite element modeling technique that can be used in any CFRP sandwich quasi-static indentation problem involving honeycomb core crushing and facesheet cracking. Material and strength properties used in all of the finite element analyses for the CFRP facesheet material and aluminum honeycomb core are shown in Tables 1 and 2, respectively.

A model of a specimen with a pristine facesheet was used to develop an accurate core crushing simulation technique. This technique was then 


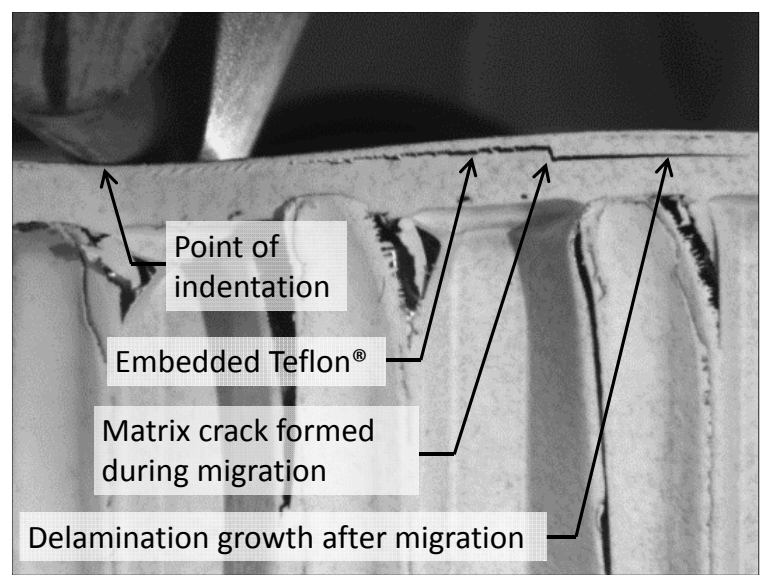

Figure 4: Final damage state of a representative test specimen.

implemented into three other finite element model variants that use different methods to simulate delamination-migration in the facesheet. The top facesheet mesh and modeling approach differ between all models, however, a generic finite element model is depicted in Figure 5 highlighting common features. The honeycomb cell walls in the core are modeled in detail using S4R reduced integration shell elements. The meshes and element types used in the upper facesheet (in contact with the indenter) are described in the following sections. The top of the core mesh is coincident with the mesh in the lowest ply stack of the top facesheet and attached via a shell-to-solid constraint. Tie constraints are used between the top of the lowest stack and the rest of the upper facesheet. Cohesive surfaces are used in all models for simulating delamination. The lower facesheet mesh shares nodes with the bottom of the core and is modeled with Abaqus ${ }^{\circledR}$ S4R reduced integration shell elements that have a composite section definition.

The indenter is modeled as a rigid surface that has a vertical displacement defined as a boundary condition forcing the quasi-static indentation. The specimen is placed on a flat fixed rigid surface. Acting as a boundary condition, this base surface provides compressive vertical support opposing the force of the indenter but allows global specimen bending where the bottom ply is free to lift off and deflect upwards. Lateral movement of the specimen is restrained by imposing a boundary condition in the x-direction on one of the end edges and in the y-direction on one of the lengthwise edges 
Table 1: Material and strength properties for facesheet (IM7/8552) [34].

\begin{tabular}{|c|c|c|c|}
\hline Property & Value & Units & Description \\
\hline$E_{11}$ & 171.4 & $\mathrm{GPa}$ & elastic moduli \\
\hline$E_{22}$ & 9.08 & GPa & $\downarrow$ \\
\hline$E_{33}$ & 9.08 & GPa & \\
\hline$G_{12}$ & 5.29 & GPa & \\
\hline$G_{13}$ & 5.29 & GPa & \\
\hline$G_{23}$ & 2.8 & GPa & \\
\hline$\nu_{12}$ & 0.32 & - & Poisson's ratio \\
\hline$\nu_{13}$ & 0.32 & - & $\downarrow$ \\
\hline$\nu_{23}$ & 0.5 & - & \\
\hline$X^{T}$ & 2325.0 & $\mathrm{MPa}$ & lamina longitudinal tensile strength \\
\hline$X^{C}$ & 1200.1 & $\mathrm{MPa}$ & lamina longitudinal compressive strength \\
\hline$Y^{T}$ & 62.3 & $\mathrm{MPa}$ & lamina transverse tensile strength \\
\hline$Y^{C}$ & 199.8 & $\mathrm{MPa}$ & lamina transverse compressive strength \\
\hline$S^{12}$ & 92.3 & $\mathrm{MPa}$ & lamina shear strength \\
\hline$G_{I c}$ & 0.277 & $\mathrm{~kJ} / \mathrm{m}^{2}$ & mode I critical energy release rate \\
\hline$G_{I I c}$ & 0.788 & $\mathrm{~kJ} / \mathrm{m}^{2}$ & mode II critical energy release rate \\
\hline$\eta_{B K}$ & 1.634 & - & Benzeggagh-Kenane (BK) law exponent \\
\hline$\rho$ & 1.55 & $\mathrm{~g} / \mathrm{cm}^{3}$ & density \\
\hline
\end{tabular}


Table 2: Material and strength properties for core (Aluminum alloy 5052-H38) [35].

\begin{tabular}{|c|c|c|c|}
\hline Property & Value & Units & Description \\
\hline$E$ & 70300 & $\mathrm{MPa}$ & elastic modulus \\
\hline$\nu$ & 0.33 & - & Poisson's ratio \\
\hline$\rho$ & 2.69 & $\mathrm{~g} / \mathrm{cm}^{3}$ & density \\
\hline$\sigma_{\text {yield }}$ & 255 & $\mathrm{MPa}$ & stress-strain material \\
\hline$\sigma_{p l, 1}$ & 255 & $\mathrm{MPa}$ & data from $[35]$ \\
\hline$\sigma_{p l, 2}$ & 290 & $\mathrm{MPa}$ & $\downarrow$ \\
\hline$\epsilon_{\text {yield }}$ & 0.0036 & - & \\
\hline$\epsilon_{p l, 1}$ & 0.0056 & - & \\
\hline$\epsilon_{p l, 2}$ & 0.14 & - & \\
\hline$\sigma_{p l, 3}$ & 275 & $\mathrm{MPa}$ & stress-strain material \\
\hline$\sigma_{p l, 4}$ & 50 & $\mathrm{MPa}$ & data added to \\
\hline$\epsilon_{p l, 3}$ & 0.15 & - & suppliment \\
\hline$\epsilon_{p l, 4}$ & 0.16 & - & plasticity law \\
\hline
\end{tabular}


of the lower facesheet. General contact is defined in the model to capture contact between the indenter and the upper facesheet, contact between the rigid base surface and the lower facesheet, and contact of the honeycomb cell walls with each other during core crushing. Vertical displacement of the

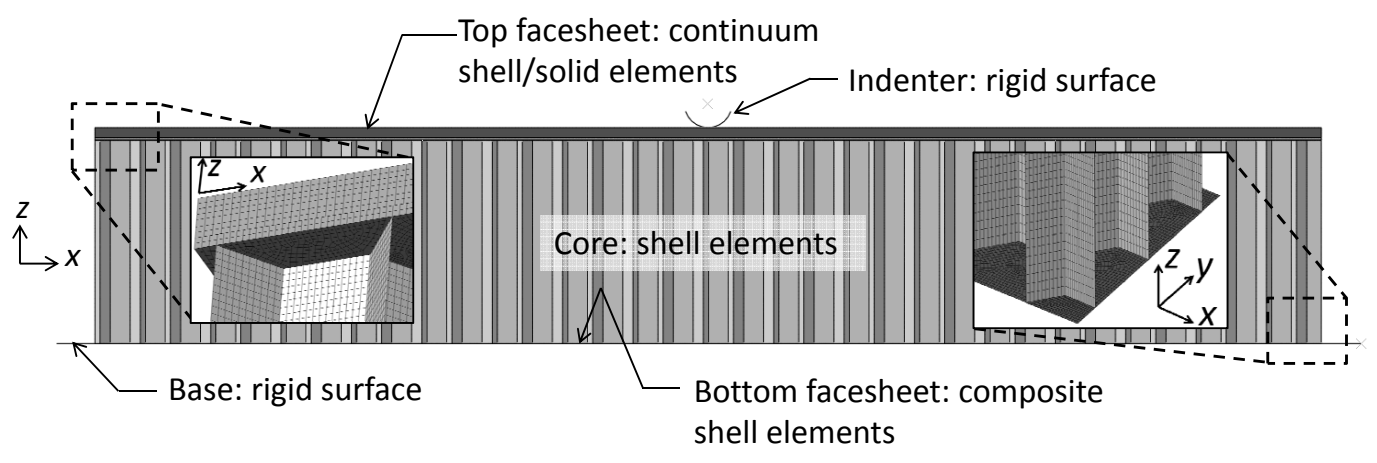

Figure 5: Finite element model overview (Abaqus screenshot).

indenter was applied as a smooth step displacement boundary condition in a dynamic analysis step lasting 2 seconds. Because mass scaling was defined to minimize model run time, it was verified that for all analyses performed, the kinetic energy was negligible compared to external work and internal strain energy. Additionally, the applied and reaction forces were confirmed to be equivalent indicating there was no appreciable global inertial force present at the end of the simulation. Mesh convergence studies were performed for the loaded facesheet and core meshes to determine a mesh size that, when refined further, does not change model results. For all models, an element size of $0.2 \mathrm{~mm}$ square was used in the core mesh in the region of interest with an aspect ratio not exceeding 4:1 elsewhere.

The first model considered corresponds to the test where no Teflon ${ }^{\circledR}$ insert was present in the loaded facesheet and any appreciable damage in the specimen consisted entirely of core crushing. Damage in the core during the crushing process consists of both structural and material failure in the form of buckling and plastic deformation, respectively. These two damage modes are simulated by enabling geometrically nonlinear behavior in the analysis solution and by defining a nonlinear isotropic plasticity material model for the aluminum that uses a Von Mises yield criterion. Material data are unavailable for the core material, aluminum alloy 5052-H39, therefore properties for aluminum alloy 5052-H38 were used instead. The nonlinear stress-strain relation 
used in the constitutive material law in the model is defined using the stressstrain values in Table 2 and shown in Figure 6. The core plasticity material model was modified slightly from the referenced material data by adding the final dashed portion of the plastic stress-strain curve. This addition to the material law simulates increased damage occurring after ultimate stress is reached. The upper facesheet was modeled with C3D8R solid elements sized at $0.38 \mathrm{~mm}$ square in the region of interest and not exceeding an aspect ratio of 4:1 elsewhere. The boundary conditions, core mesh, lower facesheet mesh, and core crushing simulation method were implemented identically in all of the following finite element models.

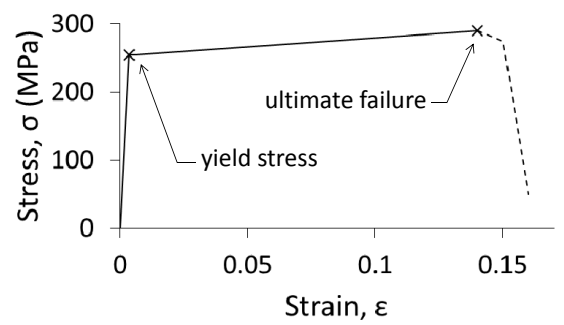

Figure 6: Al 5052-H38 constitutive material law.

Next, a finite element model was created using a cohesive zone approach (CZM) for simulating migration and delamination in the facesheet. The top facesheet mesh is composed of C3D8R solid elements sized at approximately $0.25 \mathrm{~mm}$ square in the region of interest and not exceeding an aspect ratio of 4:1 elsewhere. A damage path was prescribed in the facesheet as a cohesive surface using the parameters listed in Table 1 that follows the matrix crack and delamination geometry observed in experimentation (see Figure 4). In the cohesive damage method used, a bilinear traction-separation law is defined between two initially coincident surfaces in a mesh. The cohesive law contains an initial undamaged elastic behavior regime where the surfaces are effectively attached to one another through a high penalty stiffness. A damage initiation stress threshold is defined that initiates a softening behavior regime where the connectivity stiffness degrades linearly as the surfaces move away from one another. Separation continues until a displacement level is reached where the connectivity traction is zero and the surfaces are completely unattached [36]. When this occurs, the crack can be said to have propagated completely past this location on the surface. For damage initia- 
tion, a quadratic traction criterion was used to allow for mode mixity and is defined in equation (1). The subscripts on the traction terms, $t$, indicate the normal $(n)$ and in-plane orthogonal shear stress components $(s, t)$.

$$
\left\{\frac{\left\langle t_{n}\right\rangle}{Y^{T}}\right\}^{2}+\left\{\frac{\left\langle t_{s}\right\rangle}{S^{12}}\right\}^{2}+\left\{\frac{\left\langle t_{t}\right\rangle}{S^{12}}\right\}^{2}=1
$$

As the surfaces separate and damage evolves, a mixed mode critical energy release rate, $G_{c}$, is determined using linear softening in an energy based Benzeggagh-Kenane (BK) law [37] given by

$$
G_{c}=G_{I c}+\left(G_{I I c}-G_{I c}\right)\left(G_{I I} / G_{T}\right)^{\eta_{B K}}
$$

In equation (2), the Mode II energy release rate, $G_{I I}$, and total energy release rate, $G_{T}$, are determined as part of the analysis solution. Values for critical Mode I energy release rate, critical Mode II energy release rate, and the BK exponent, $G_{I c} ; G_{I I c} ;$ and $\eta_{B K}$, respectively, are given in Table 1.

A parametric study was conducted to determine that a value for the viscous stabilization coefficient of $2 \times 10^{-4}$ in the Abaqus ${ }^{\circledR}$ cohesive property definition was the maximum that could be used without affecting model results. The purpose for this was to reduce solution time as much as possible without sacrificing accuracy. The CZM was used as a means to verify the overall behavior of the model in the context of this study.

A finite element model similar to the CZM was created using the built-in Abaqus $^{\circledR}$ continuum damage model in the facesheet (ACDM) for the matrix crack simulation instead of a cohesive surface. The ACDM utilizes the Hashin damage initiation criterion and its associated material stiffness degradation method for fiber reinforced composites [33, 38] as it is implemented in Abaqus/Explicit ${ }^{\circledR} 6.13$ for facesheet elements in the vicinity of the matrix crack. Most of the facesheet in the ACDM is modeled as an elastic material because inclusion of the continuum damage model throughout the facesheet results in a prohibitive level of computational demand. Damage evolution occurs according to a stress displacement relation and is such that material stiffness, given by the elasticity matrix in equation (3), is reduced by increasing the parameters $d_{m}$ and $d_{f}$, corresponding to matrix and fiber damage, respectively, from zero to a maximum of 1.0 as damage increases. Multiple delamination paths are prescribed as cohesive surfaces that extend in both directions from the edge of the Teflon ${ }^{\circledR}$ strip (i.e., where migration occurs) at 
interfaces above and below the $90^{\circ}$ ply stack in which the intralaminar matrix crack forms. The Hashin/CDM damage technique has a two-dimensional (i.e., membrane) implementation in Abaqus ${ }^{\circledR} 6.13$ and therefore can only be used in plane stress elements. The upper facesheet in the ACDM is composed of SC8R reduced integration continuum shell elements sized at approximately $0.25 \mathrm{~mm}$. All stacks have two elements through the thickness except for the stack where the migration occurs where three elements are defined in an effort to increase the fidelity of the migration process.

$$
\begin{gathered}
C=\left[\begin{array}{ccc}
\left(1-d_{f}\right) E_{1} & \left(1-d_{f}\right)\left(1-d_{m}\right) \nu_{12} E_{1} & 0 \\
\left(1-d_{f}\right)\left(1-d_{m}\right) \nu_{12} E_{1} & \left(1-d_{m}\right) E_{2} & 0 \\
0 & 0 & \left(1-d_{s}\right) G D
\end{array}\right] \\
D=1-\left(1-d_{f}\right)\left(1-d_{m}\right) \nu_{12} \nu_{21}
\end{gathered}
$$

A second continuum damage method with a three-dimensional formulation well suited for problems with non-negligible transverse shear was used. The deformation gradient decomposition (DGD) method of Leone [39] was implemented in a finite element model (DGDM) in place of the Hashin/CDM formulation used in the ACDM to simulate migration. The DGD method involves embedding a cohesive law in a three-dimensional solid material model to represent the opening and closing of a matrix crack. It is analogous to the smeared crack CDM approach of Camanho et al. [40], in which the strain tensor $\epsilon$ is additively decomposed into elastic strain, $\epsilon_{e l}$, and cracking strain, $\epsilon_{c r}$, components:

$$
\epsilon=\epsilon_{e l}+\epsilon_{c r}
$$

In the DGD method, the deformation gradient tensor $F$ is additively decomposed into two parts: a new deformation gradient tensor, $F_{b u l k}$, which represents the bulk material deformation, and a normalized cohesive displacementjump vector, $\delta$, which represents the crack opening:

$$
F=F_{b u l k}+\frac{1}{L_{c}} R_{c r} \delta
$$

where $L_{c}$ is the characteristic element length, and $R_{c r}$ defines the current orientation of the crack with respect to the element reference configuration. 
The magnitude of the cohesive displacement-jump is determined by minimizing the difference between the cohesive traction on the crack plane and the projection of the bulk material stress on the crack plane. The embedded cohesive law is based on the explicit cohesive element implementation of Gonzalez et al. [41].

Conventional strain-based continuum damage models (such as the ACDM) that represent a crack by softening components of the material stiffness tensor do not perform well when subjected to large shear deformations in geometrically nonlinear finite element problems. Load transfer across matrix cracks and the prediction of spurious secondary failure mechanisms can occur if the local material orientation is defined as if the cracked material were continuous, as in equation (3). Not accounting for how the orientation of material in cracked and non-cracked continua differ from one another introduces error into the definition of the current crack orientation and material directions. The DGD method addresses this issue and allows for the orientations of the material and the crack to be defined accurately for geometrically nonlinear problems subject to large shear deformations.

Two versions of the DGDM were considered, one with the formulation described and the other with the contribution of transverse shear on crack initiation and growth removed. As in the ACDM, delamination paths are prescribed as cohesive surfaces that extend in both directions from the migration location at interfaces above and below the $90^{\circ}$ ply stack. The upper facesheet is composed of C3D8R reduced integration solid elements. The mesh is discretized in the thickness direction with two elements per ply stack except for the $90^{\circ}$ stack where migration occurs where there are three elements in the thickness direction. The DGD method is implemented here as a VUMAT user material subroutine for Abaqus/Explicit ${ }^{\circledR}$ 6.13. Comparison between the two DGDM results will indicate the role transverse shear stress plays in the simulation.

Finally, to investigate the importance of details specific to the migration such as matrix crack orientation angle and the relevance of matrix crack growth energy dissipation, three modified versions of the CZM were created. Each of these models has a different predefined migration crack angle. The angles considered from the horizontal plane were $90^{\circ}, 70^{\circ}$ (as observed experimentally), and $45^{\circ}$. In the case of the $90^{\circ}$ crack orientation, two simulations were performed; one with a cohesive surface implemented along the damage path as in the other CZMs, and the other with the cohesive zone omitted entirely from the migration portion of the damage path. In the latter, the 
matrix crack is still defined as two surfaces initially in contact with each other, but they are free to separate uninhibited.

\section{Results and Discussion}

\subsection{Core Crushing}

The first tests performed were on specimens that did not contain a Teflon ${ }^{\circledR}$ insert in the loaded facesheet. In these tests, only core damage occurs for indenter displacements less than $1.25 \mathrm{~mm}$. A deformed plot of the corresponding model shown in Figure 7 shows that honeycomb cells are deformed and buckled in the same manner as seen in testing. Further validation of the model is achieved by comparing the deformed shape of one edge of the loaded top facesheet in the model with that of the test where digital image correlation data were recorded. A good correlation of deformed facesheet shape and force displacement data is shown in Figures 8 and 9, respectively. The initial nonlinear portion of the experimental curves was found to be a result of uneven specimen seating on the test stand that was not accounted for in the models.

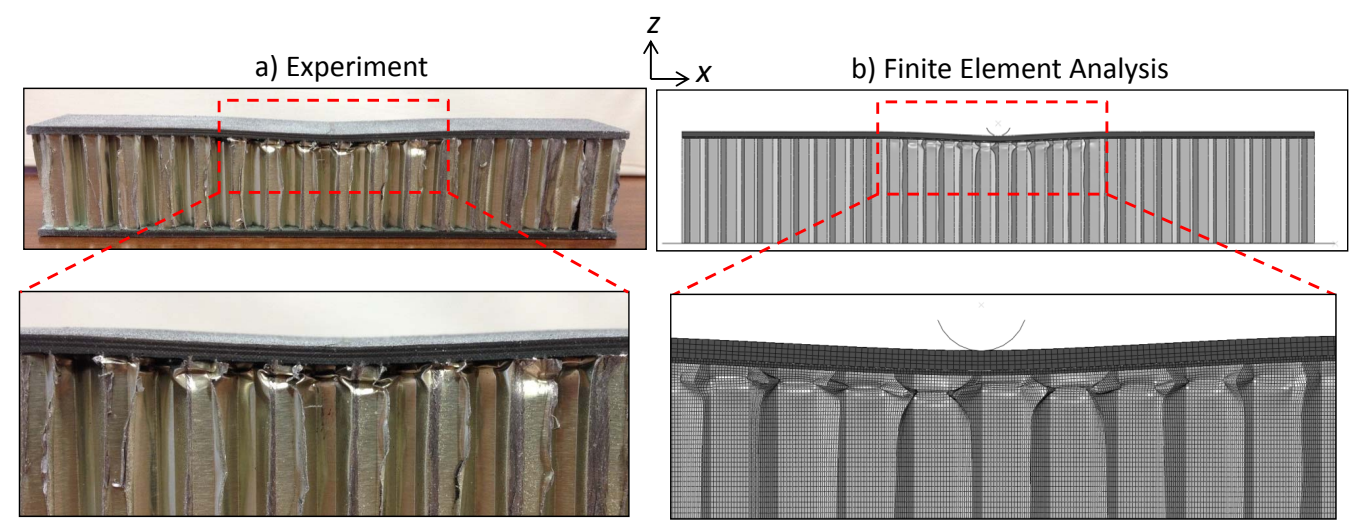

Figure 7: Comparison of honeycomb core deformation between experiment and finite element analysis (no facesheet damage occurs in test or model).

The comparisons in Figures 7-9 suggest that in cases where no facesheet damage occurs, the finite element model is capable of simulating core crushing 


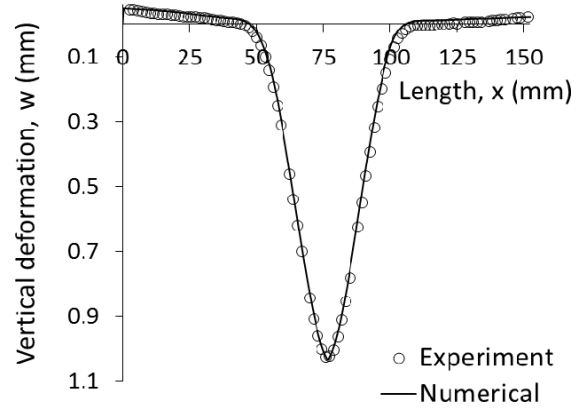

Figure 8: Facesheet deformation data correlation for core damage only.

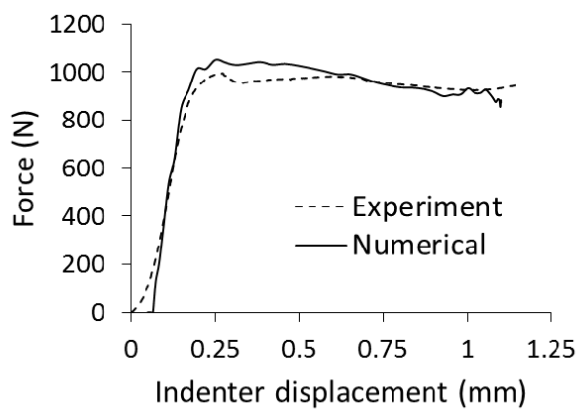

Figure 9: Indenter force displacement data correlation with core damage only.

and the associated facesheet deformed shape along its entire length. Therefore, the internal stress state in the facesheet should be well captured at all locations.

\subsection{Facesheet Damage}

Figure 10 shows the final damage state of a representative test specimen compared with predictions from the three facesheet damage simulation models. Each of the models predicts the correct sequence of events in the damage process seen in testing. In the following order, the test and all simulations undergo: 1) honeycomb cell buckling, 2) a matrix crack growth through the $90^{\circ}$ ply stack below the Teflon ${ }^{\circledR}$ strip (i.e., migration), and 3) delamination propagation away from the migration location on a new ply interface. Force displacement data from two experiments (Specimens 1 and 2) and the simulations are plotted in Figure 11. Sequential damage events are identified along the Specimen 2 curve. The sudden change in slope is due to buckling of the 

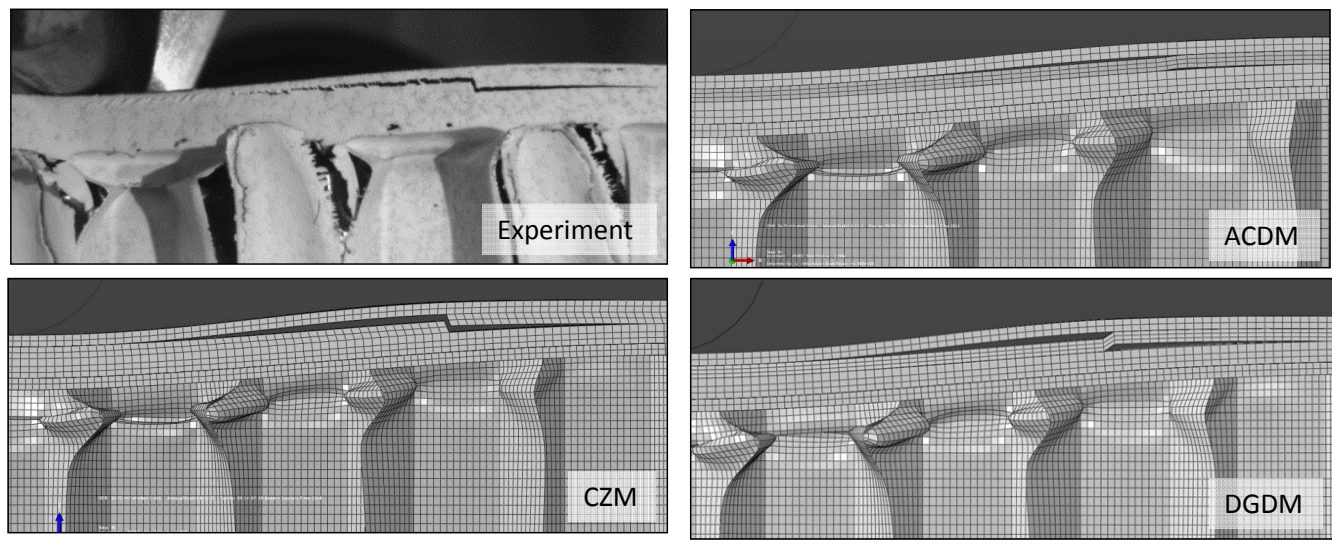

Figure 10: Visual correlation of facesheet and core damage.

honeycomb cells in the vicinity of the indenter and while the nonlinearity from the initial part of the tests is again evident, the critical load for initiating core crushing is well predicted. Migration and subsequent delamination occur at the slight peak seen in the experimental curve near an indentation displacement of $0.6 \mathrm{~mm}$.

Delamination growth is shown in Figure 12 for experimental data and the CZM, ACDM, and two DGDM models. The first data point on each of the curves was taken at the end of the migration process. The nonlinear test specimen behavior observed during experimentation affects how the results in Figure 12 should be interpreted. Figure 11 shows that at a given indenter displacement, the applied indentation force may be different between an experiment and the models. One means of data correlation in Figure 12 between tests and models is to compare migration and delamination growth relative to the onset of core crushing or force magnitude, rather than relative to the absolute indenter displacement. All of the models except the ACDM predict migration to occur at an indentation approximately $0.2 \mathrm{~mm}$ - $0.4 \mathrm{~mm}$ beyond that of core crushing onset. The same behavior was seen in test specimens. Delamination growth after migration, however, tends to be delayed in the models. In the experiments, delamination began immediately after migration and maintained a constant rate until the end of the test. The models, to varying degrees, show a period immediately after migration where delamination is either delayed or occurs at a reduced rate. The magnitude of 


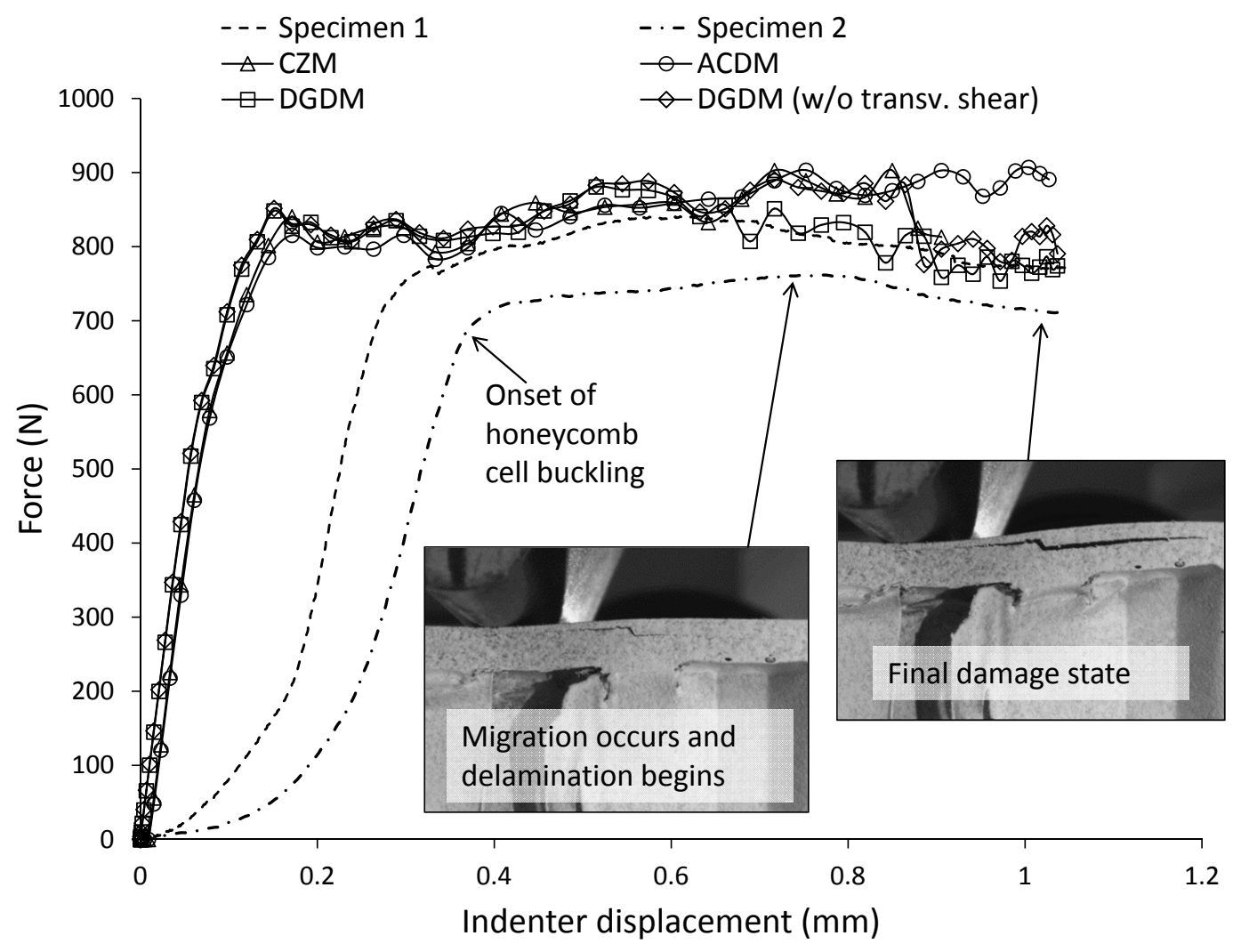

Figure 11: Facesheet damage simulation: delamination growth data correlation.

this apparent inaccuracy of the models, however, appears small compared to the magnitude of experimental data scatter seen in both Figures 11 and 12 . Eventually an indentation displacement is reached where all of the models predict a delamination growth rate that matches rates seen in testing.

Of all of the models, the CZM has the closest correlation with test data and provides further confidence in the overall model behavior. The CZM's predictive capability is limited, however, because the migration path must be predefined at the beginning of an analysis. This limitation prevents the CZM from being a practical tool to use for general problems. The ACDM and the DGDMs do not have this limitation as the migration location is not predefined by the user. In the ACDM and DGDM, the number of possible 
delamination paths was also increased by adding cohesive surfaces at both the upper and lower ply interfaces of the $90^{\circ}$ stack where migration occurs.

Though the facesheet damage process is simulated correctly by the ACDM in terms of sequence of events, the migration and delamination prediction does not have a good correlation with the experiments when compared to the other models. This may be explained by the fact that, as implemented in Abaqus ${ }^{\circledR}$ 6.13, the material model cannot be affected by or degrade stiffness associated with transverse shear stress. The transverse matrix crack that occurs during migration allows the upper and lower regions of the damaged facesheet to separate normally from each other. If a continuum damage approach is used where the degraded elements representing the matrix crack are still connected in terms of the mesh, they must undergo a large uninhibited shear deformation for the delamination crack surfaces to separate properly. The shear deformation occurring across the elements representing the matrix crack in the ACDM and DGDM can be seen in Figure 10.

Further appreciation for the importance of transverse shear stress and the applicability of the ACDM formulation for this problem is gained by comparing results from the two DGDM models. The DGDM has the ability to affect the transverse shear stiffness as damage develops as well as include transverse shear stress in the damage initiation criterion. In addition, the DGDM is derived especially for cases which exhibit large shear deformations. The DGDM has the best experimental data correlation of all of the continuum damage methods considered in this study. When its transverse shear contribution is removed, effectively rendering it as a two-dimensional or membrane implementation, the migration and delamination predictions are similar to those of the ACDM. This observation indicates that the ACDM is not well suited (or intended) for use in a three-dimensional problem such as this where the transverse shear stress influences the damage process. Similarly, comparing results of the two DGDM models indicates that transverse shear effects should be included in a delamination-migration simulation. This conclusion is confirmed by noticing that in Figure 10 the lack of transverse shear stiffness softening in the migration elements arrests the Mode I opening of the delamination in the ACDM compared to other models and to the experiment. Both the DGDM and the CZM, approximately equivalent in terms of accuracy, underpredict the delamination length until the end of the test. 


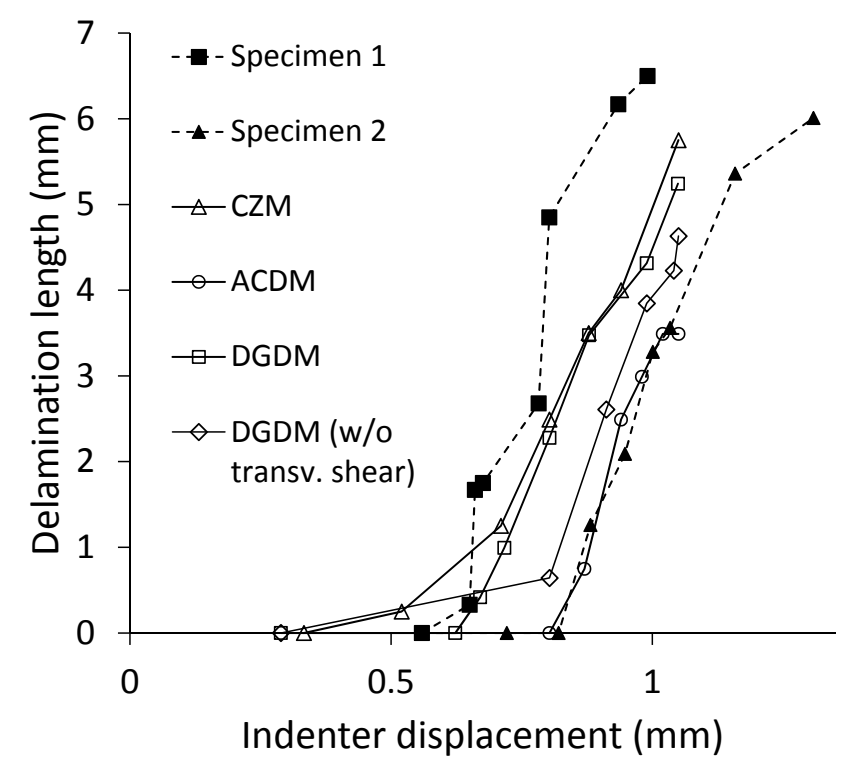

Figure 12: Facesheet damage simulation: indenter force displacement correlation.

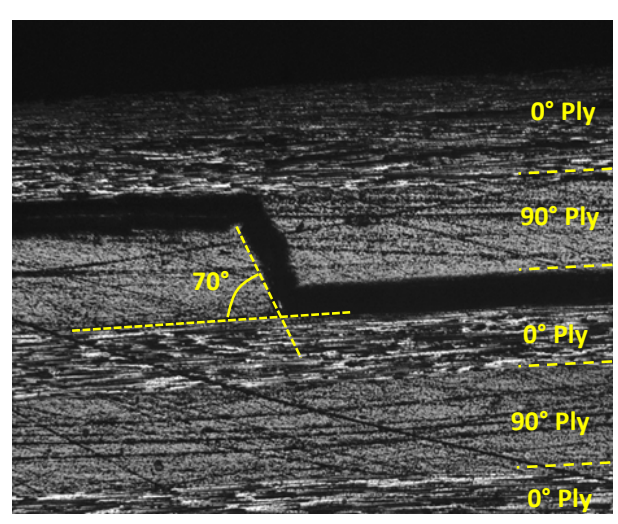

Figure 13: Orientation of matrix crack formed during migration.

The CZM and the DGDM both include representation of and influence on damage growth of the orientation of the matrix crack formed during migration. They also both include energy dissipation for the matrix crack through use of a cohesive law. Accounting for migration orientation and matrix crack 
growth energy dissipation adds complexity and increases computational demand of a numerical damage model. If these two details can be neglected without compromising accuracy, future development of simulation models may be simplified. In testing, migration was observed to occur at an angle of $70^{\circ}$ from the horizontal as shown in Figure 13 by a micrograph image of the matrix crack. Force displacement and delamination growth are shown in Figures 14 and 15, respectively, for several CZMs with a varying migration orientation.

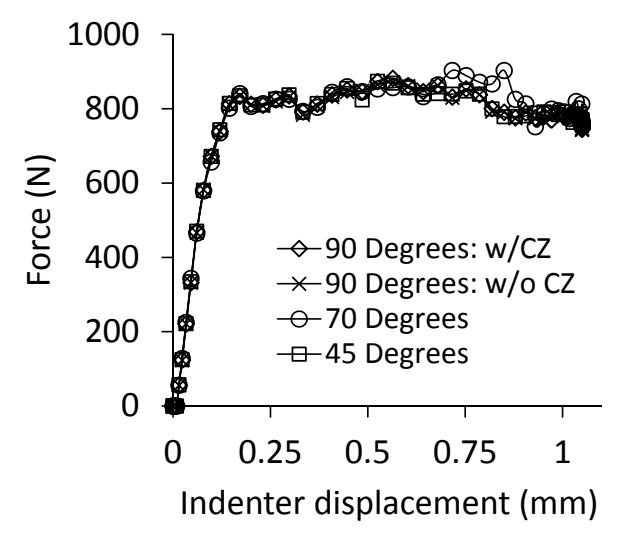

Figure 14: Migration orientation CZM: force displacement.

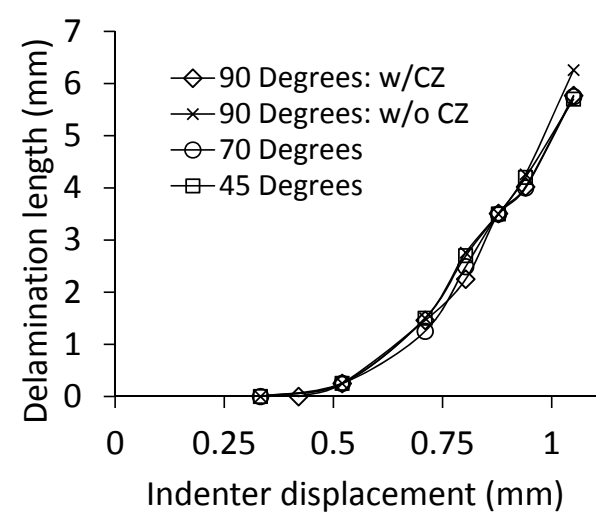

Figure 15: Migration matrix crack. 
While some minor differences in model results can be seen, it is evident from Figures 14 and 15 that the angle of the migration crack has very little effect overall on the simulation. Even when the cohesive zone is omitted entirely from the mesh surfaces defining the migration, the results are not affected. This indicates that intraply matrix cracking is responsible for only a small amount of energy dissipation when compared to that which is dissipated by delamination and core crushing and that which is stored as elastic strain energy. Results from the migration orientation study and ACDM results suggest that while knowing the occurrence of and location of migration may be important, explicitly simulating crack orientation and associated energy dissipation may have a negligible effect on numerical simulation of a laminate damage process in a sandwich structure that includes core crushing and delamination-migration.

\section{Conclusion}

Using a novel CFRP sandwich indentation experiment as a source for validation data, numerical simulation of delamination-migration in a laminate was investigated. A quasi-static indentation load was applied to CFRP aluminum honeycomb core sandwich test specimens that contained an embedded delamination in the top facesheet. Under an indentation load, the embedded flaw migrates to a new ply interface location and then continues to delaminate in a stable manner due to support from the core on the top loaded facesheet. Several finite element damage modeling techniques for damage in the facesheet were evaluated and compared. This exercise resulted in a general finite element methodology that includes high fidelity core crushing and laminate damage simulation techniques that can be applied in general to CFRP honeycomb core sandwich indentation problems.

For simulation of delamination-migration in the sandwich facesheet, cohesive zone and three contiuum damage techniques were considered. The continuum damage type methods used were the built-in Abaqus ${ }^{\circledR} 6.13$ Hashin/ continuum damage model (ACDM) and Leone's deformation gradient decomposition method with and without transverse shear effects included (DGDM). The CZM is the most accurate model for simulating this experiment though it is limited in predictive capability as the delamination-migration location and path must be predefined. In the ACDM, though the migration location was predicted correctly, its initiation and subsequent delamination was delayed and never reached the extent seen in testing. The DGDM without trans- 
verse shear effects included showed a slight improvement in accuracy over the ACDM. The DGDM with trsnsverse shear effects included was shown to have approximately the same level of accuracy as the CZM and is a more useful tool in practice as the migration path does not need to be known $a$ priori.

Comparison of the results from the different models indicates that transverse shear stress is relevant in a delamination-migration simulation. Additionally, it was found that varying the orientation of the matrix crack between $90^{\circ}, 70^{\circ}$, and $45^{\circ}$ as well as omitting a damage model entirely from the migration matrix crack surfaces had a negligible effect on the simulation. This suggests that details such as crack orientation and energy dissipation associated with intraply matrix cracks during a delamination-migration damage process may not influence a numerical simulation of this type of damage process in a sandwich structure.

\section{Acknowledgments}

\section{References}

[1] J. Ratcliffe, W. Jackson, J. Schaff, Compression strength prediction of impact-damaged composite sandwich panels, in: Proceedings of the American Helicopter Society 60th Annual Forum, Baltimore, MD, 2004.

[2] E. S. Greenhalgh, C. Rogers, P. Robinson, Fractographic observations on delamination growth and the subsequent migration through the laminate, Composites Science and Technology 69 (14) (2009) 2345-2351.

[3] C. Canturri, E. S. Greenhalgh, S. T. Pinho, J. Ankersen, Delamination growth directionality and the subsequent migration processes-the key to damage tolerant design, Composites Part A: Applied Science and Manufacturing 54 (2013) 79-87.

[4] J. G. Ratcliffe, M. W. Czabaj, T. K. O'Brien, A test for characterizing delamination migration in carbon/epoxy tape laminates NASA/TM2013-218028.

[5] H. Suemasu, Y. Tanikado, Damage growth behavior and interlaminar fracture resistance of CFRP laminates under shear fracture mode, Advanced Composite Materials (accepted for publication) (2014) 1-16. 
[6] N. D. Carvalho, B. Chen, S. Pinho, J. Ratcliffe, P. Baiz, T. Tay, Modeling delamination migration in cross-ply tape laminates, Composites Part A: Applied Science and Manufacturing (accepted for publication) (2015)-.

[7] M. McElroy, J. Ratcliffe, M. Czabaj, J. Wang, F. Yuan, A numerical and experimental study of damage growth in a composite laminate (paper no. 281), in: Proceedings of the American Society for Composites: 29th Technical Conference, La Jolla, California, September 8-10, American Society for Composites, 2014.

[8] E. F. Rybicki, M. Kanninen, A finite element calculation of stress intensity factors by a modified crack closure integral, Engineering Fracture Mechanics 9 (4) (1977) 931-938.

[9] R. Krueger, Virtual crack closure technique: history, approach, and applications, Applied Mechanics Reviews 57 (2) (2004) 109-143.

[10] E. F. Rybicki, T. D. Hernandez, J. E. Deibler, R. C. Knight, S. S. Vinson, et al., Mode I and mixed mode energy release rate values for delamination of graphite/epoxy test specimens, Journal of composite materials 21 (2) (1987) 105-123.

[11] G. Barenblatt, The formation of equilibrium cracks during brittle fracture. General ideas and hypotheses. Axially-symmetric cracks, Journal of Applied Mathematics and Mechanics 23 (3) (1959) 622-636.

[12] M. De Moura, J. Gonçalves, A. Marques, P. T. De Castro, Modeling compression failure after low velocity impact on laminated composites using interface elements, Journal of Composite Materials 31 (15) (1997) $1462-1479$.

[13] P. P. Camanho, C. G. Dávila, Mixed-mode decohesion finite elements for the simulation of delamination in composite materials, NASA/TM2002-211737.

[14] Q. Yang, B. Cox, Cohesive models for damage evolution in laminated composites, International Journal of Fracture 133 (2) (2005) 107-137. 
[15] M. Wisnom, Modelling discrete failures in composites with interface elements, Composites Part A: Applied Science and Manufacturing 41 (7) (2010) 795-805.

[16] N. Moes, J. Dolbow, T. Belytschko, A finite element method for crack growth without remeshing, Int. J. Numer. Meth. Engng 46 (1) (1999) 131-150.

[17] A. Matzenmiller, J. Lubliner, R. Taylor, A constitutive model for anisotropic damage in fiber-composites, Mechanics of materials 20 (2) (1995) 125-152.

[18] F. Van der Meer, L. Sluys, S. Hallett, M. Wisnom, Computational modeling of complex failure mechanisms in laminates, Journal of Composite Materials 46 (3) (2011) 603-623.

[19] C. Bouvet, S. Rivallant, J.-J. Barrau, Low velocity impact modeling in composite laminates capturing permanent indentation, Composites Science and Technology 72 (16) (2012) 1977-1988.

[20] E. González, P. Maimí, P. Camanho, A. Turon, J. Mayugo, Simulation of drop-weight impact and compression after impact tests on composite laminates, Composite Structures 94 (11) (2012) 3364-3378.

[21] E. V. Iarve, M. R. Gurvich, D. H. Mollenhauer, C. A. Rose, C. G. Dávila, Mesh-independent matrix cracking and delamination modeling in laminated composites, International Journal for Numerical Methods in Engineering 88 (8) (2011) 749-773.

[22] P. O. Sjoblom, J. T. Hartness, T. M. Cordell, On low-velocity impact testing of composite materials, Journal of composite materials 22 (1) (1988) 30-52.

[23] W. C. Jackson, C. Poe, The use of impact force as a scale parameter for the impact response of composite laminates, Journal of Composites Technology and Research 15 (1993) 282-282.

[24] I. Choi, C. Hong, New approach for simple prediction of impact force history on composite laminates, AIAA journal 32 (10) (1994) 2067-2072. 
[25] B. Russell, T. Liu, N. Fleck, V. Deshpande, The soft impact of composite sandwich beams with a square-honeycomb core, International Journal of Impact Engineering 48 (2012) 65-81.

[26] B. L. Buitrago, C. Santiuste, S. Sánchez-Sáez, E. Barbero, C. Navarro, Modelling of composite sandwich structures with honeycomb core subjected to high-velocity impact, Composite structures 92 (9) (2010) 20902096.

[27] L. Aktay, A. F. Johnson, B.-H. Kröplin, Numerical modelling of honeycomb core crush behaviour, Engineering Fracture Mechanics 75 (9) (2008) 2616-2630.

[28] C. Foo, G. Chai, L. Seah, A model to predict low-velocity impact response and damage in sandwich composites, Composites Science and Technology 68 (6) (2008) 1348-1356.

[29] Y. Aminanda, B. Castanie, J.-J. Barrau, P. Thevenet, Experimental analysis and modeling of the crushing of honeycomb cores, Applied Composite Materials 12 (3-4) (2005) 213-227.

[30] M. Yamashita, M. Gotoh, Impact behavior of honeycomb structures with various cell specifications-numerical simulation and experiment, International Journal of Impact Engineering 32 (1) (2005) 618-630.

[31] H. Zhao, G. Gary, Crushing behaviour of aluminium honeycombs under impact loading, International Journal of Impact Engineering 21 (10) (1998) 827-836.

[32] Correlated Solutions, VIC-3D Reference Manual, 2010.

[33] Dassault Systems, Abaqus 6.13 Analysis User Manual, 2013.

[34] P. P. Camanho, P. Maimí, C. Dávila, Prediction of size effects in notched laminates using continuum damage mechanics, Composites Science and Technology 67 (13) (2007) 2715-2727.

[35] Material Property Data, Aluminum 5052-H38, http://www.matweb.com (2014). 
[36] A. Turon, C. G. Davila, P. P. Camanho, J. Costa, An engineering solution for mesh size effects in the simulation of delamination using cohesive zone models, Engineering fracture mechanics 74 (10) (2007) 1665-1682.

[37] M. Benzeggagh, M. Kenane, Measurement of mixed-mode delamination fracture toughness of unidirectional glass/epoxy composites with mixedmode bending apparatus, Composites Science and Technology 56 (4) (1996) 439-449.

[38] I. Lapczyk, J. A. Hurtado, Progressive damage modeling in fiberreinforced materials, Composites Part A: Applied Science and Manufacturing 38 (11) (2007) 2333-2341.

[39] F. Leone, Deformation gradient tensor decomposition for representing matrix cracks in fiber-reinforced materials (in preperation).

[40] P. Camanho, M. Bessa, G. Catalanotti, M. Vogler, R. Rolfes, Modeling the inelastic deformation and fracture of polymer composites-part II: smeared crack model, Mechanics of Materials 59 (2013) 36-49.

[41] E. González, P. Maimí, A. Turon, P. Camanho, J. Renart, Simulation of delamination by means of cohesive elements using an explicit finite element code, Computers, Materials \& Continua (CMC) 9 (1) (2009) 51. 